\title{
Conversion Hallucinations in a Patient with Pseudohypoparathyroidism
}

\author{
John Kasckow, MD, Ph.D. \\ Duke University Medical Center, Durham North Carolina
}

Allan Maltbie, MD

Duke University Medical Center, Durham, North Carolina

Follow this and additional works at: https://jdc.jefferson.edu/jeffjpsychiatry

Part of the Psychiatry Commons

\section{Let us know how access to this document benefits you}

\section{Recommended Citation}

Kasckow, MD, Ph.D., John and Maltbie, MD, Allan (1989) "Conversion Hallucinations in a Patient with Pseudohypoparathyroidism," Jefferson Journal of Psychiatry. Vol. 7 : Iss. 2 , Article 6.

DOI: https://doi.org/10.29046/JJP.007.2.004

Available at: https://jdc.jefferson.edu/jeffjpsychiatry/vol7/iss2/6

This Article is brought to you for free and open access by the Jefferson Digital Commons. The Jefferson Digital Commons is a service of Thomas Jefferson University's Center for Teaching and Learning (CTL). The Commons is a showcase for Jefferson books and journals, peer-reviewed scholarly publications, unique historical collections from the University archives, and teaching tools. The Jefferson Digital Commons allows researchers and interested readers anywhere in the world to learn about and keep up to date with Jefferson scholarship. This article has been accepted for inclusion in Jefferson Journal of Psychiatry by an authorized administrator of the Jefferson Digital Commons. For more information, please contact: JeffersonDigitalCommons@jefferson.edu. 


\title{
Conversion Hallucinations in a Patient with Pseudohypoparathyroidism
}

\author{
John Kasckow, M.D., Ph.D. \\ Allan Maltbie, M.D.
}

\section{INTRODUCTION}

There are few case reports in the literature which discuss psychiatric disturbances in patients with pseudohypoparathyroidism (PHP) (1,2). PHP is a disease characterized by an inadequate response to parathyroid hormone. Often these patients are obese with a short, stocky build and moon-shaped face. Mental retardation is present in as many as $10 \%$ of these patients; a reversible dementialike syndrome can also occur $(2,3)$. In addition, Capgras' syndrome has been observed in pseudohypoparathyroid patients $(1,2)$. In these last two reports the authors concluded that the psychosis was probably organically-based. Hay et al (1) noted in their case report that psychotic symptoms were correlated with EEG abnormalities; furthermore, remission of these symptoms was correlated with normalization of the EEG tracing.

Conversion disorders have long been known to medicine (4-6). The revised version of the 3rd Diagnostic and Statistics Manual (7) states that a conversion disorder involves a loss or change in physical functioning not attributable to a known physiological mechanism. The symptoms are not under voluntary control as in malingering. There must be a temporal relationship between the loss of function and some psychological stress. Psychogenic pain shares many of the characteristics of conversion disorder, except that the presenting complaint is not a loss in physical functioning but rather chronic pain (8).

Organic disorders often present with a co-existing conversion disorder (6). There can be a remarkable amount of overlap between the organic disorder and the co-existing conversion reaction; this obscures the clinical presentation and typically accounts for marked exaggeration of symptom complaints and disabilities out of keeping with the observed pathology. For example, it is not uncommon for a patient with a true seizure disorder to also have pseudoseizures (6). It should be remembered that the presence of organic pathology never rules out a coexistent conversion phenomenon since the latter can present in a similar fashion. Often an organic process may be worsened by emotional factors; likewise, organic disorders may serve as a model for the development of conversion reactions.

Conversion hallucinations are a specific type of conversion symptom, most frequently presenting as visual or auditory hallucinations (9-11). Because they 
are not accompanied by any other disturbance of thought content or form, they are referred to as "pseudopsychoses." These hallucinations are perceived by the patient as being real and thus are considered "true" hallucinations. Conversion hallucinations may also exist as "pseudo-hallucinations," in which the patient experiences unreal sensory perceptions but has insight into the fact that the images are not real $(11,12)$.

In this case report, we present a pseudohypoparathyroid patient with depression and hallucinations. In contrast to the above reports, we explain the hallucinations psychodynamically as a conversion "pseudopsychosis" rather than an organically-based psychosis.

\section{CASE REPORT}

A 31-year-old white female had been admitted multiple times to the general psychiatry ward at a university hospital. For the past seven years she had had a history of recurrent depression; each episode manifested itself with weight loss, loss of sleep, early morning awakenings, crying spells, and suicidal thinking. She had been treated successfully in the past for depression with either psychotropic drugs or ECT (13).

The patient's medical history was complicated. Since age 15 she had been hospitalized more than fifty times for evaluation or treatment of PHP and/or depression. She was diagnosed with PHP at age 22. She was obese with a short stature, metacarpal and metatarsal hypoplasia, hyperphosphaturia, decreased urinary cAMP and decreased renal phosphate responses to parathormone (14). She had a systemic adenylate cyclase receptor deficiency and later developed other medical problems including pulmonary sarcoidosis (without CNS involvement), hypothyroidism, hyperlipidemia, pancreatitis, amenorrhea, and gastroesophageal reflux with peptic ulcers, all of which were inactive by the time we began to treat her.

Because of her long stays in the hospital, she had major disruptions in her social development. She had become socially isolated. She complained of feeling rejected by her family for being the only sibling who remained unmarried and without children. She had few friends and had no dates with men other than one isolated relationship, a brief affair with a sailor on a cruise. In addition, she lost her job as a nurse's assistant during one of her depressive episodes and was placed on disability because of her medical problems. Psychological testing was performed repeatedly and consistently revealed strong hysterical and passive aggressive tendencies.

On the fourth psychiatric admission prior to the writing of this report she developed auditory hallucinations consisting of birds chirping continuously in both ears. Around the same time, she noticed "bugs" in the periphery of her vision which disappeared whenever she tried to focus on them with her central vision. She obtained relief from these hallucinations only twice. The first remission occurred following a session of hypnosis in which she was rid of the chirping birds for several weeks; a second session of hypnosis performed several months later resulted in a remission of several hours.

The initial hypnotherapy focused on the removal of the birds one by one while she was in a trance. She was given the suggestion that the birds were on the windowsill. It was suggested that they fly away one by one. The auditory hallucinations ceased completely with this treatment. At this point we reasoned that the hallucinations must be conver- 
sional since organically-based hallucinations would not be expected to cease with hypnotherapy.

She was hospitalized three more times for depression. Just prior to the second of these hospitalizations, she started hearing voices of close acquaintances. Soon after admission she developed myoclonic-like jerks which were initially diagnosed as true myoclonus. These did not respond to primidone but cleared spontaneously when ignored by staff. At the same time, she started seeing "bugs" which would crawl all over her and make her itch. When these hallucinations were most intense, she would simultaneously hear male voices exclaiming "you can't get me now."

She was able to count the number of "bugs" per square tile on the floor. On two occasions, her therapist stepped purposely on one of the squares and the patient believed that several of the "bugs" had been killed. She had no other changes in mental status during these episodes.

During this hospitalization as well as the five previous admissions to our hospital for depression and hallucinations, her laboratory values remained within normal limits. This included serum electrolytes, carbon dioxide, blood urea nitrogen, glucose, creatinine, calcium and, thyroid and liver function tests. Her EEG was stable, revealing mildly elevated background activity with some slowing during drowsiness. No epileptiform activity was seen. Her CT scan remained stable revealing calcification of the basal ganglia. Brain MRI was repeatedly normal.

During the hospital stay described above, she was maintained on the following medications: propranolol $40 \mathrm{mgs}$ po bid, levothyroxine $150 \mathrm{mgs}$ po qd, ranitidine 150 mgs po qd, vitamin D 50,000 units qd, and nortriptyline 75 mgs po qhs (with therapeutic blood levels). She had been on the above regimen for six months preceding admission. Three weeks prior to her hospitalization, she was placed on thiothixene $5 \mathrm{mgs}$ po tid, which was ineffective in controlling her pseudopsychotic symptoms. Following admission, she received thiothixene $2 \mathrm{mg}$ po qid for 12 days. This was replaced with an "antipsychotic cocktail" four times a day which initially consisted of 30 cc of cola with $2 \mathrm{mgs}$ thiothixene, $12.5 \mathrm{mgs}$ hydroxyzine, and a mixture of vitamins. Over two days, the thiothixene was tapered and discontinued in a single-blind manner and she was given the remaining cocktail components as a prn for hallucinations and agitation. She used this regularly with an anxiolytic response. The nortriptyline was continued as above.

Daily individual psychotherapy was continued throughout the hospitalization and was combined with hypnotherapy. Like her previous hypnotherapy, her hypnotherapy at this time suggested that she attempt to limit her field of vision until the "bugs" disappeared completely. Her psychotherapy was of an insight oriented focus; it dealt with her desire to be an independent and mature woman, a desire that clearly was not possible in her sick role identity. During psychotherapy, she recalled an earlier episode from 1980 at a different hospital when sodium amytal was given for an episode of aphonia (not previously known to us). This interview had been taped and shown to her. She remembered writhing on the table and talking like a small girl. Her posture, facial expression and voice resembled that of a little girl. She stated "I don't want to be a little girl like that." She realized that when hallucinating she would react like a little girl; become nervous and appear helpless. She also realized that during these times she would seek help from the hospital staff or from her parents when at home. The conflict between the "little girl" use of sick role behavior to influence others with that of the desired identity of an adult woman who enjoys male relationships desired roles was utilized effectively in psychotherapy. She realized the need to give up the "sick little girl" behavior. As she 
explored her feelings for the little girl, she was able to grieve and cry about the "sick girl" part of her and at least temporarily, leave it in the past. As she grieved her mood and affect improved. Within three weeks after initiating this psychotherapeutic approach and four weeks after discontinuing thiothixene, her hallucinations ceased. She left the hospital in good spirits, planning new social activities with local psychotherapeutic treatment arranged. Five months later she experienced a relapse of depression. The family refused to participate in family treatment and she was hospitalized again for suicidal thinking and depression.

\section{DISCUSSION}

This case report typifies the features of chronic conversion disorders (6) where secondary gain rather than primary gain is the predominant feature. Primary gain refers to the reduction of tension and conflict through neurotic defense mechanisms - for instance the sudden paralysis of one's right arm in an angry confrontation with one's mother. Secondary gain refers to unconsciously motivated gain from the external world; this would include monetary compensation or increased attention from others as a result of the symptoms. This patient's hallucinations served to intensify or expand her established sick role and attracted attention from those around her. She was able to divert most of her family's energy toward herself when she was "sick." Through her illness behavior she was the center of attention. While maintaining control over others through dependency demands, she also, over time, alienated both her family and acquaintances, making them resent her. Consequently, intensified illness behavior was needed to rekindle their concern. This was effectively accomplished through her conversional symptoms.

The negative aspect of this "sick role" relationship with others was that she had failed to experience any lasting friendships or any intimate adult relationships. By maintaining the sick role she could gain power and attention from others but at the price of her development into independent adulthood. Her sexual development was clearly halted. As mentioned above her only encounter with the opposite sex was a brief affair with a sailor, over whom she had fantasied and pined since.

Other features seen in chronic conversion disorders which she exhibited include: 1) distant onset of symptoms, 2) presence of multiple conversion symptoms and 3) poor prognosis. With regards to the latter point, she was, in fact, hospitalized again at the time of this writing with a recurrence of her symptoms.

In having an accompanying depressive illness, this patient is also typical of patients with conversion disorders. McKegney (14), Lazare (5), and Ford and Folks (4) state that conversion symptoms often accompany depression, schizophrenia, and/or characterologic disorders. Our patient had depression and although she did not have an actual Axis II diagnosis she exhibited hysterical and passive aggressive character traits.

In conversion hallucinosis, visual and auditory hallucinations are most 
prevalent (9-11). Tactile hallucinations are a much less common manifestation of conversion hallucinosis (15). This patient also experienced "true" hallucinations as opposed to "pseudohallucinations" in so far as she perceived the hallucinations as being real.

We do not believe that the hallucinations were part of an organically-based psychotic process. There were no changes in laboratory values or EEG to support an organic explanation of her psychiatric symptoms. Although antipsychotics have been known to contribute to psychosis (17) this was unlikely for three reasons: 1) She was not on antipsychotics the other two times she hallucinated. 2) Her doses of thiothixene were very low and 3) remission was achieved by a behavioral/psychotherapeutic approach with a rapid symptomatic response to therapeutic interventions. Rather, psychodynamic explanations can account for the symptoms. Simply put, she relied on these symptoms to maintain herself in the sick role, she was conflicted over whether to be assertive, independent and sexual in the adult sense, versus maintaining dependence on her family in a more regressive child-like fashion which could be justified by sickness. The latter choice was predominant during the time she had hallucinations. In a regressive sick role she could have others treat her like a child showering her with a great deal of nurturing. This secondary gain kept her enmeshed with her family and unable to break away into independence. Only by working through this in psychotherapy could she gain adulthood.

The atypical nature of her hallucinations and multiplicity of complaints were additional clues to the fact that this phenomenon was a pseudopsychosis. This stands in marked contrast to the other reported cases of PHP, where the symptomatology was felt to be part of an organically based psychotic process.

The patient's case also typifies how chronic medical illness can disrupt psychosocial development. Children and adolescents with chronic medical problems face repeated anxiety over separation issues, depleted physical and psychic energy as well as heightened somatic sensations and preoccupations with both physical defects and vulnerability. Commonly they experience regression, denial, withdrawal, hypochondriasis, conversion and depression. They often develop into adults with dependent, anxious personalities (18-20). This patient had significant disruptions in her emotional development, related to her medical problems which resulted in the expression of the above psychopathology.

\section{REFERENCES}

1. Hay G, Jolley D, Jones R: A case of the capgras syndrome in association with pseudohypoparathyroidism. Acta Psychiatr Scand 50:73-77, 1974

2. Preskorn S, Reveley A: Pseudohypoparathyroidism and capgras syndrome. $\mathrm{Br} \mathrm{J}$ Psychiatry 133:34-37, 1978

3. Wells C: Organic syndromes: dementia, in Comprehensive Textbook of Psychiatry, 4th ed. Edited by Kaplan H and Saddock B. Baltimore, Williams and Wilkins, 1985

4. Ford C, Folks D: Conversion disorders: An overview. Psychosomatics 26:371-383, 1985 
5. Lazare A: Current concepts in psychiatry: Conversion symptoms. New Engl J Med 305:745-748, 1981

6. Maltbie A: Conversion Disorders, in Signs and Symptoms in Psychiatry. Edited by Cavenar J, Brodie H. Philadelphia, Lippincott, 1983

7. American Psychiatric Association: Diagnostic and Statistical Manual of Mental Disorders, 3rd edition, revised. Washington, D.C., 1987

8. Maltbie A: Chronic pain, in Biomedical Psychiatric Therapeutics. Edited by Sullivan J, Sullivan P. Boston, Butterworth Publishers, 1984

9. Anrade $\mathrm{C}$, Srinath $\mathrm{K}$ : True auditory hallucinations as a conversion symptom. $\mathrm{Br} \mathrm{J}$ Psychiatry 148:100-102, 1986

10. Fitzgerald A, Wells C: Hallucinations as a conversion reaction. Diseases of the Nervous System 38:381-383, 1977

11. Modai I, Sirota P, Cygielman G, et al: Conversion hallucinations. J Nerv Ment Dis 168:564-565, 1980

12. Hollander M, Boszormenyi-Nagy I: Hallucinations as an ego experience. Arch Neurol Psychiatry 80:93-97, 1958

13. McCall W, Coffey C, Maltbie A: Successful electroconvulsive therapy in a depressed patient with pseudohypoparathyroidism. Electroconvulsive Therapy 5:114-117, 1989

14. Prezner M, Haussler M: Normocalcemic pseudo-hypoparathyroidism: Association with normal vitamin D3 metabolism. Am J Med 66:503-508, 1979

15. McKegney $F$ : The incidence and characteristics of patients with conversion reactions: A general hospital consultation service sample. Am J Psychiatry 124:542-545, 1967

16. Bishop E, Holt A: Pseudopsychosis: A reexamination of the concept of hysterical psychosis. Comprehensive Psychiatry 21:150-161, 1980

17. Davis JF: Antipsychotic drugs in Comprehensive Textbook of Psychiatry, 4th ed. Edited by Kaplan H and Saddock B. Baltimore, Williams and Wilkins, 1985

18. Pfeffer CR: Childrens reactions to illness, hospitalization and surgery, in Comprehensive Text book of Psychiatry 4th edition. Edited by Kaplan $\mathrm{H}$ and Saddock B. Baltimore Williams and Wilkins, 1985

19. Prugh DG, Strub EM, Sands HH, Kirschbaum RM, Levitan EA: A study of the emotional reactions of children and families to hospitalization and illness. Am J Orthopsychiatry 23:78-106, 1953

20. Rutter M: Stress, coping and development: Some issues and some questions. J Child Psychol Psychiatry 22:323-356, 1981 